\title{
A study of nitride inclusions in chondrites: Tracers for nebular processes?
}

\author{
JAN LEITNER ${ }^{1}$, CHRISTIAN VOLLMER ${ }^{2}$, DENNIS \\ HARRIES $^{3}$, JÁNOS KODOLÁNYI ${ }^{1}$, ULRICH OTT ${ }^{1}$ AND \\ PETER HOPPE ${ }^{1}$
}

${ }^{1}$ Max Planck Institute for Chemistry

${ }^{2}$ Institut für Mineralogie, Universität Münster

${ }^{3}$ Friedrich-Schiller-Universität Jena

Presenting Author: jan.leitner@mpic.de

Nitrogen is the most abundant component in Earth's atmosphere and one of the key elements for the evolution of Earth's biosphere. However, the types of nitrogen carriers, their abundances and $\mathrm{N}$-isotopic compositions are not well constrained for all the potential terrestrial building blocks. Chondritic meteorites contain small quantities of various nitrides. $\mathrm{Si}_{3} \mathrm{~N}_{4}$, TiN, and sinoite $\left(\mathrm{Si}_{2} \mathrm{~N}_{2} \mathrm{O}\right)$ are common accessory phases of enstatite chondrites (ECs). Nitrides in ordinary (OCs) and carbonaceous chondrites (CCs), however, have been scarcely reported [e.g., 1-6]. Here, we report the discovery of Si-, Cr- and Fe-nitride in several carbonaceous chondrites. The average Nisotopic compositions of nitrides from CCs differ significantly from those in ECs [7], and we also observe variations between different $\mathrm{CC}$ groups. Generally, nitrogen becomes isotopically heavier in nitrides from EC-(OC-) through CV\&CM to CR$\mathrm{CH} \& \mathrm{CB}$ chondrites. This could be indicative of increasing amounts of outer Solar System nitrogen contributing to the respective $\mathrm{Si}$ - and $\mathrm{Cr}$-nitrides, and may reflect different heliocentric distances of the formation regions [8]. We also observe that the $\mathrm{N}$-isotopic compositions of these nitrides are sometimes significantly different from those of their host meteorites and meteorite groups [e.g.,7,9]. This seems to suggest several different nitrogen reservoirs and/or different alteration pathways for the various $\mathrm{N}$-carriers within a given meteorite group, and could also explain the bulk $\mathrm{N}$-isotopic variations observed for, e.g., the OCs [10].

Acknowledgements: The DFG is acknowledged for funding this project in the course of the SPP 1833.

References : [1] Russell S. S. et al. (1995) Meteoritics 30, 399. [2] Grady M. M. \& Pillinger C. T. (1993) EPSL 116, 165. [3] Weisberg M. K. et al. (1988) EPSL 91, 19. [4] Weber D. et al. (1994) Meteoritics 29, 547. [5] Meibom A. et al. (2007) ApJ 656, L33. [6] Harries D. et al. (2015) Nat. Geosci. 8, 97. [7] Leitner J. et al. (2018) GCA 235, 153. [8] Füri E. \& Marty B. (2015) Nat. Geosci. 8, 515. [9] Kung C.-C. and Clayton R. N. (1978) EPSL 38, 421. [10] Sugiura N. et al. (1998) Meteorit. Planet. Sci. 33, 463. 